\title{
Assessment of growth condition for a candidate probiotic, Shewanella algae, isolated from digestive system of a healthy juvenile Penaeus monodon.
}

\begin{abstract}
To conquer disease problem in shrimp industries, probiotic biocontrol is a well-known remedy now. The antagonistic ability of separated isolates from different parts of juvenile P. monodon was screened against shrimp Vibrio pathogens, V. parahaemolyticus and V. alginolyticus. The most antagonistic effect was observed for an isolate that primarily identified as Shewanella algae using conventional method followed by Biolog GN and GP microplates. Since adaptability to the host optimum cultural condition of the target organism is of the great importance, response surface methodology, with central composite design, was applied to assess log cell count response of $\mathrm{S}$. algae in different incubation conditions. Therefore, four independent variables were assumed as: temperature $\left(10-50^{\circ} \mathrm{C}\right), \mathrm{pH}(6-10)$, $\mathrm{NaCl}$ concentration $(0-50 \%)$ and time $(12-60 \mathrm{~h})$. The coefficients of multiple determinations (R2) for the responses log cell count of S. algae being 0.827 . Temperature was the merely significant independent variable that affected the log cell count of the candidate probiotic. The candidate probiotic was revealed a reasonable growth response in quite wide range of temperature, $\mathrm{pH}$ and $\mathrm{NaCl}$ concentration in which the maximum levels were in same range of optimum shrimp culture.
\end{abstract}

Keyword: Bacterial growth; P. monodon; Probiotic; S. algae; V. alginolyticus; V. parahaemolyticus 